Article

\title{
In Vitro Studies of Polyhedral Oligo Silsesquioxanes: Evidence for Their Low Cytotoxicity
}

\author{
Anna Janaszewska ${ }^{1}$, Kinga Gradzinska ${ }^{2}$, Monika Marcinkowska ${ }^{1}$, \\ Barbara Klajnert-Maculewicz ${ }^{1,3}$ and Wlodzimierz A. Stanczyk ${ }^{2, *}$ \\ ${ }^{1}$ Department of General Biophysics, Faculty of Biology and Environmental Protection, \\ University of Lodz, Pomorska 141/143, Lodz 90-236, Poland; E-Mails: ankuj@ poczta.onet.pl (A.J.); \\ m_monika123@interia.eu (M.M.); aklajn@biol.uni.lodz.pl (B.K.-M.) \\ ${ }^{2}$ Centre of Molecular and Macromolecular Sciences, Sienkiewicza 112, Lodz 90-236, Poland; \\ E-Mail: kgradzin@cbmm.lodz.pl \\ ${ }^{3}$ Leibniz-Institut für Polymerforschung Dresden e.V., Hohe Strasse 6, Dresden 01069, Germany \\ * Author to whom correspondence should be addressed; E-Mail: was@ cbmm.lodz.pl; \\ Tel.: +48-42-680-3208.
}

Academic Editor: Aldo Boccaccini

Received: 26 June 2015 / Accepted: 6 September 2015 / Published: 10 September 2015

\begin{abstract}
As scientific literature considers polyhedral oligosilsesquioxanes (POSS) as potential drug delivery systems, it is necessary to check their impact on mammalian cells. Toxicity of octaammonium chloride salt of octaaminopropyl polyhedral oligomeric silsesquioxane (oap-POSS) towards two cell lines: mouse neuroblastoma (N2a) and embryonic mouse hippocampal cells (mHippoE-18) was studied. Experiments consisted of analysis of a cell cycle, cell viability, amount of apoptotic and necrotic cells, and generation of reactive oxygen species (ROS). POSS caused a shift in the cell population from the $\mathrm{S}$ and $\mathrm{M} / \mathrm{G}_{2}$ phases to the $\mathrm{G}_{0} / \mathrm{G}_{1}$ phase. However, the changes affected less than $10 \%$ of the cell population and were not accompanied by increased cytotoxicity. POSS did not induce either apoptosis or necrosis and did not generate reactive oxygen species. A cytotoxicity profile of POSS makes it a promising starting material as drug carrier.
\end{abstract}

Keywords: POSS; silsesquioxane; in vitro toxicity; MTT assay; cell cycle; apoptosis; necrosis; reactive oxygen species 


\section{Introduction}

An intense search for new transporting systems of anti-cancer drugs is urgently needed. It is believed that a targeted therapy can both diminish severe side-effects and increase effectiveness of chemotherapy. Such a therapy requires combination of targeted molecules (e.g., folic acid residues) and chemotherapeutics. This can be achieved thanks to multivalency that characterizes some nanosystems such as dendrimers [1,2] or hyperbranched polymers [3,4], which possess plenty of functional groups. Despite promising results achieved for these polymers, there is still a point to look for simpler, more effective, and cheaper solutions.

Although silsesquioxanes were synthesized much earlier than other popular nanosystems, they are now regarded as a next generation materials in terms of their potential effectiveness in biomedicine as targeted carriers of anticancer drugs. Studies on polyhedral oligo silsesquioxanes (POSS) were limited to conjugation with fluorescent dyes [5], incorporation into dendrimeric systems [6,7], development of dental nano-composites [8] and cardiovascular implants [9]. Silsesquioxanes were scarcely studied as drug delivery systems and never as moieties covalently conjugated with drugs, even though they are free of the disadvantages of polymers as polydispersity of hyperbranched polymers or laborious syntheses of dendrimers.

The main objective of this work was to study in vitro effect caused by polyhedral oligo silsesquioxanes oap-POSS cages (Figure 1). Such cages are characterized by small dimensions (their diameter is approximately $1.5 \mathrm{~nm}$ ) and are considered as a nanomodel of silica. The long-term goals include using POSS as drug carriers in a targeted anti-cancer therapy. Selective delivery of such systems might be achieved by attaching both anticancer drugs and folic acid residues to the same cage. This approach was never investigated in the case of POSS although was widely explored for other nanosystems.

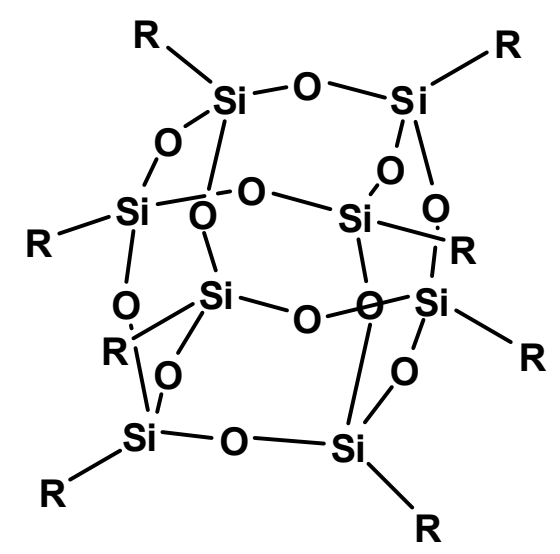

Figure 1. The structure of octaammonium chloride salt of octaaminopropyl polyhedral oligomeric silsesquioxane (oap-POSS), $\mathrm{R}=-\left(\mathrm{CH}_{2}\right)_{3} \mathrm{NH}_{3} \mathrm{Cl}$.

In order to make an important step towards a new targeted drug delivery system, more is needed to be known about the impact of silsesquioxanes on a cell condition. In the literature, there is a lack of data concerning in vitro studies of POSS. Therefore, we undertook toxicity evaluation of POSS towards two cell lines: mouse neuroblastoma (N2a) and embryonic mouse hippocampal cells (mHippoE-18). The choice of these cell lines comes from our current studies on POSS-anticancer drugs nanocomposites. A 
detailed analysis was performed that included POSS impact on: a cell cycle, cell viability, amount of apoptotic and necrotic cells, and generation of free radical species.

\section{Results and Discussion}

Cells at different stages of the cell cycle can be distinguished by their DNA content. Experimentally it is achieved by incubation of cells with a fluorescent dye-propidium iodide - that binds to DNA, followed by analysis of the fluorescence intensity of individual cells in a flow cytometer and thereby distinguishing cells in the $\mathrm{G}_{0} / \mathrm{G}_{1}, \mathrm{~S}$, and $\mathrm{M} / \mathrm{G}_{2}$ phases of the cell cycle [10]. N2a and mHippoE-18 cells were used to analyze cell cycle kinetics following treatment with POSS that lasted either $24 \mathrm{~h}$ or $48 \mathrm{~h}$. For the control samples of both cell lines (Figure 2, Table 1), over half of the cell population was in the $\mathrm{G}_{0} / \mathrm{G}_{1}$ phase. There were also distinct populations of cells in the $\mathrm{M} / \mathrm{G}_{2}$ phase (almost $30 \%$ ) and the $\mathrm{S}$ phase (less than 15\%). In the case of mHippo-E cells, incubation with POSS for $24 \mathrm{~h}$ did not cause a statistically significant effect, whereas a twofold increase of the incubation time caused a shift in the cell population from the $S$ and $M / G_{2}$ phases to the $G_{0} / G_{1}$ phase. N2a cells were more susceptible to POSS and the same trend was observed even after the 24-hour incubation. After $48 \mathrm{~h}$ the effect was more pronounced.

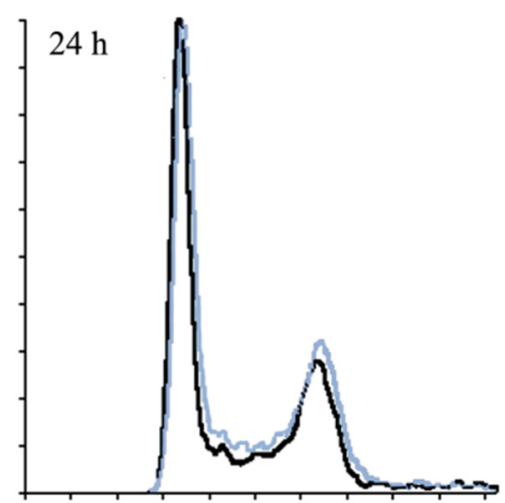

(a)

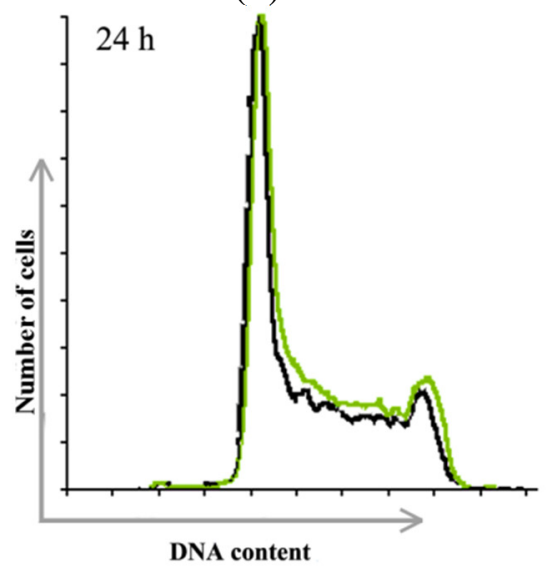

(c)

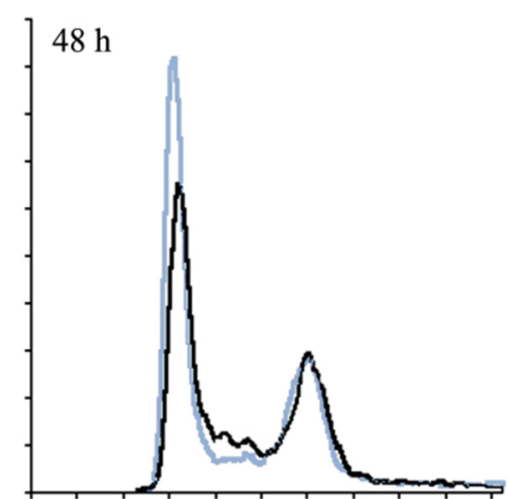

(b)

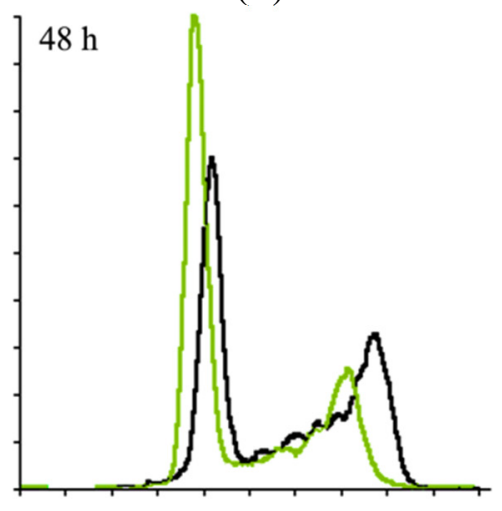

(d)

control $=\mathrm{N} 2 \mathrm{a}+\mathbf{1 m M}$ POSS

mHippoE-18 + 1mM POSS

Figure 2. Cell population histograms for N2a cells (a,b) and mHippoE-18 cells (c,d) that were untreated (control) and upon incubation with $1 \mathrm{mM}$ POSS for $24 \mathrm{~h} \mathrm{(a,c)} \mathrm{and} 48 \mathrm{~h} \mathrm{(b,d).}$ 
Table 1. Cell cycle analysis for control untreated cells and cells treated with $1 \mathrm{mM}$ POSS. Each result represents a mean and SD taken from $n \geqslant 6$ wells from 3 independent experiments. $(*) \mathrm{p}<0.05 ;(* *) \mathrm{p}<0.001$.

\begin{tabular}{ccccc}
\hline & $\mathbf{N 2 a}$ & $\mathbf{G}_{\mathbf{0}} / \mathbf{G}_{\mathbf{1}}$ & $\mathbf{S}$ & $\mathbf{M} / \mathbf{G}_{\mathbf{2}}$ \\
\hline \multirow{2}{*}{$24 \mathrm{~h}$} & Control & $52.70 \pm 0.52$ & $13.23 \pm 0.93$ & $29.77 \pm 0.80$ \\
& $1 \mathrm{mM}$ POSS & $54.57 * \pm 0.49$ & $11.40 * \pm 0.50$ & $29.53 \pm 0.61$ \\
\hline \multirow{2}{*}{$48 \mathrm{~h}$} & Control & $53.67 \pm 0.65$ & $13.57 \pm 0.70$ & $30.40 \pm 1.36$ \\
& $1 \mathrm{mM}$ POSS & $62.63 * * \pm 0.91$ & $11.57 \pm 0.90$ & $22.83 * * \pm 0.17$ \\
\hline \multirow{2}{*}{$\mathbf{m H i p p o E - 1 8}$} & $\mathbf{G}_{\mathbf{0}} / \mathbf{G} \mathbf{1}$ & $\mathbf{S}$ & $\mathbf{M} / \mathbf{G 2}$ \\
\hline \multirow{2}{*}{$24 \mathrm{~h}$} & Control & $54.17 \pm 0.97$ & $12.57 \pm 0.68$ & $29.13 \pm 0.40$ \\
& $1 \mathrm{mM}$ POSS & $52.83 \pm 0.49$ & $11.83 \pm 0.95$ & $30.77 \pm 0.40$ \\
\hline \multirow{2}{*}{$48 \mathrm{~h}$} & Control & $48.50 \pm 0.87$ & $13.33 \pm 0.15$ & $28.93 \pm 1.10$ \\
& $1 \mathrm{mM}$ POSS & $57.17 * * \pm 0.29$ & $9.67 * * \pm 0.55$ & $26.23 * * \pm 0.60$ \\
\hline
\end{tabular}

Cell cycle analysis is a very complex process since several groups of proteins are involved in its regulation. To verify whether the observed cell arrest in the $G_{0} / G_{1}$ phase was a sign of a toxic effect of POSS, we checked the amount of apoptotic and necrotic cells by a double staining method with Annexin V-FITC and propidium iodide. We observed no statistically significant changes in the level of apoptotic, necrotic, and viable cells (Figure 3).

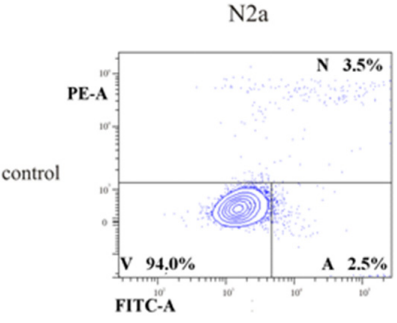

(a)

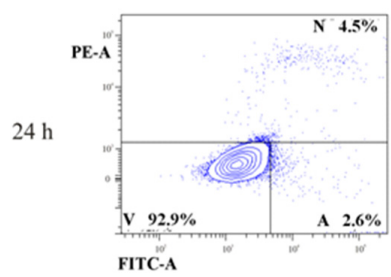

(c)

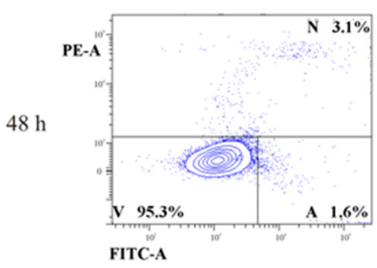

(e)

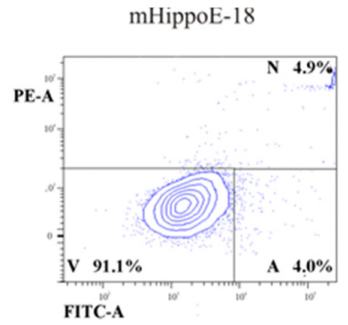

(b)

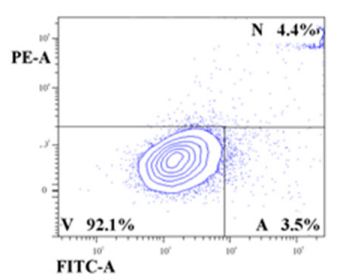

(d)

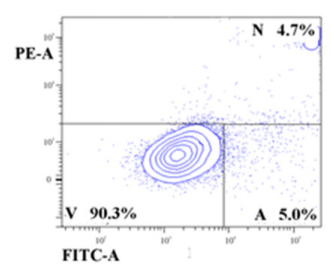

(f)

Figure 3. Flow cytometry analysis of the ability of POSS to induce necrosis or apoptosis assayed by Annexin V-FITC and PI fluorescence (V-viable cells; A-apoptotic cells; $\mathrm{N}$-necrotic cells; FITC-A-fluorescence of Annexin V; PE-A-fluorescence of PI). Fractions of apoptotic and necrotic cells after $24 \mathrm{~h}$ and $48 \mathrm{~h}$ incubation with POSS in a concentration of $1 \mathrm{mM}$ are presented for $\mathrm{N} 2$ a cells $(\mathbf{a}, \mathbf{c}, \mathbf{e})$ and mHippoE-18 cells $(\mathbf{b}, \mathbf{d}, \mathbf{f})$. 
There were more than $90 \%$ viable cells after $48 \mathrm{~h}$ incubation with POSS for both cell lines. This result was further conformed by an MTT assay (Figure S1 in Supplementary Material).

Recently, it has become clear that reactive oxygen species (ROS) control the cell cycle by influencing the activity of enzymes involved in cell cycle regulation [11,12]. On the other hand, it is known that some nanosystems, such as dendrimers or nanoparticles, are able to generate ROS [13,14]. Therefore, we checked whether POSS could produce ROS. It was determined by using $\mathrm{H}_{2}$ DCF-DA that is suitable for the estimation of total oxidative activity in living cells. For both tested cell lines we found no ROS generation upon addition of POSS neither after $24 \mathrm{~h}$ incubation nor after $48 \mathrm{~h}$ incubation (Figure S2 in Supplementary Material).

\section{Experimental Section}

\subsection{Materials}

POSS was made as described in [15] from (3-aminopropyl) triethoxysilane (Sigma Aldrich, Poznan, Poland). All cell culture reagents were purchased from Gibco (Darmstadt, Germany). Flasks and multiwell plates were obtained from Nunc (Darmstadt, Germany). MTT (3-[4,5-dimethylthiazol-2-yl]-2,5-diphenyltetrazolium bromide), PI (propidium iodide) and deoxyribonuclease-free ribonuclease A were purchased from Sigma Aldrich (Poznan, Poland). Trypan blue, $\mathrm{H}_{2}$ DCF-DA (2', 7' -dichlorodihydrofluorescein), AnnexinV were purchased from BD Biosciences (Franklin Lakes, NJ, USA). Embryonic mouse hippocampal cell line (mHippoE-18) was purchased in CEDARLANE Laboratories Limited (Burlington, ON, Canada). Mouse neuroblastoma cell line (N2a) was purchased from Banca Biologica e Cell Factory (Genova, Italy).

\subsection{Cell Culture}

Mouse neuroblastoma (N2a) and embryonic mouse hippocampal cells (mHippoE-18) were grown in DMEM medium supplemented with $2 \mathrm{mM}$ glutamine and $10 \%$ (v/v) fetal bovine serum (FBS). Cells were cultured in T-25 culture flasks at $37{ }^{\circ} \mathrm{C}$ in humidified atmosphere containing $5 \% \mathrm{CO}_{2}$ and subcultured every 2 or 3 days. Cells were harvested and used in experiments after obtaining 80\%-90\% confluence. The number of viable cells was determined by the trypan blue exclusion assay using Countess Automated Cell Counter (Invitrogen, Waltham, CT, USA). Cells were seeded either in a flat bottom 96-well plates at a density of $1.0 \times 10^{4}$ cells/well in $100 \mu \mathrm{L}$ of an appropriate medium or in a flat bottom 24 -well plates at a density of $1.0 \times 10^{5}$ cells/well in $1 \mathrm{~mL}$ of an appropriate medium. After seeding, plates were incubated for $24 \mathrm{~h}$ in order to attach cell to the plates.

\subsection{Cell Cycle Analysis}

A cell cycle was analysed using fluorescence of propidium iodide (PI), which binds to DNA. Fluorescence intensity of PI is directly proportional to DNA content [16]. Cells were seeded in 24-well plates at a density of $1.0 \times 10^{5}$ cells/well and incubated with POSS for $24 \mathrm{~h}$ and $48 \mathrm{~h}$ at $37{ }^{\circ} \mathrm{C}$ in humidified atmosphere containing $5 \% \mathrm{CO}_{2}$. Next, cells were washed with phosphate buffered saline (PBS) and fixed with 96\% frozen ethanol before being placed in a freezer for $24 \mathrm{~h}$. Cells collected by centrifugation were washed twice with PBS and resuspended in PBS containing $10 \mathrm{mM}$ Tris HCI 
(pH 7.5), $5 \mathrm{mM} \mathrm{MgCl} 2,10 \mu \mathrm{g} / \mathrm{mL}$ PI and $10 \mu \mathrm{g} / \mathrm{mL}$ deoxyribonuclease-free ribonuclease A. The cell suspension was incubated in a dark room at $4{ }^{\circ} \mathrm{C}$ for $20 \mathrm{~min}$ and the fluorescence was measured using a BD Bioscences (Franklin Lakes, NJ, USA) LSR II flow cytometer.

\subsection{In Vitro Cytotoxicity}

The influence of POSS on the cell viability was determined using an MTT assay [17]. Briefly, to the 96-well plates containing cells at the density of $1.0 \times 10^{4}$ cells/well different concentrations of POSS were added. Cells were incubated with POSS for $24 \mathrm{~h}$ and $48 \mathrm{~h}$. After the incubation period cells were washed with PBS. Next, $50 \mu \mathrm{L}$ of a $0.5 \mathrm{mg} / \mathrm{mL}$ solution of MTT in PBS was added to each well and cells were further incubated under normal culture conditions for $4 \mathrm{~h}$. After incubation the residue MTT solution was removed and the obtained formazan precipitate was dissolved in dimethyl sulfoxide (DMSO) $(100 \mu \mathrm{L} /$ well). The conversion of the tetrazolium salt (MTT) to a colored formazan by mitochondrial and cytosolic dehydrogenases is a marker of cell viability. Before the absorbance measurement plates were shaken for $1 \mathrm{~min}$ and the absorbance at $570 \mathrm{~nm}$ was measured with the PowerWave HT Microplate Spectrophotometer (BioTek, Winooski, VT, USA).

\subsection{Detection of Apoptotic and Necrotic Cells}

Detection of apoptotic and necrotic cells was performed by Annexin V and propidium iodide (PI) staining. Annexin V is a protein that specifically binds to phosphatidylserine-phospholipid translocated from the inner layer of the plasma membrane to the outer layer in early apoptotic cells. The cell membrane of apoptotic cells stained with Annexin V conjugated with fluorescein isothiocyanate (FITC) is impermeable to the red fluorescent dye PI, which is able to penetrate the interior of necrotic cells. Therefore, this method is suitable to differentiate between intact, apoptotic and necrotic cell populations. Viable cells show a low level of green fluorescence, while apoptotic cells exhibit an increased level of green fluorescence. Necrotic cells reveal both, red and green fluorescence [18]. Cells were seeded in 24-well plates at the density of $1.0 \times 10^{5}$ cells/well and incubated with silsesquioxane for $24 \mathrm{~h}$ and $48 \mathrm{~h}$, as in the previous experiments. Next, cells were washed with PBS, suspended in $500 \mu \mathrm{L}$ of binding buffer (delivered from the producer) and a mixture consisting of $5 \mu \mathrm{L}$ of Annexin V fluorescein isothiocyanate (FITC) and $5 \mu \mathrm{L}$ of PI was added to cell suspension. Samples were incubated at room temperature for 20 min in dark. Fluorescence intensity was measured with a Becton Dickinson LSR II flow cytometer. For control purposes the apoptotic and necrotic cells were used. Apoptosis was induced by camptothecin $(80 \mu \mathrm{M})$ and necrosis was induced by pentachlorophenol $(0.6 \mu \mathrm{M})$ (data not shown).

\subsection{Detection of Intracellular ROS Formation}

The intracellular reactive oxygen species (ROS) level is an important marker of oxidative stress. Relative ROS production was determined by using 2', 7'-dichlorodihydrofluorescein $\left(\mathrm{H}_{2} \mathrm{DCF}-\mathrm{DA}\right)$ that is suitable for the estimation of total oxidative activity in living cells. The detection is based upon the formation of fluorescent dichlorofluorescein (DCF) from nonfluorescent $\mathrm{H}_{2}$ DCF-DA. $\mathrm{H}_{2}$ DCF-DA, while incubated with cells, is cleaved by cytosolic esterases to $\mathrm{H}_{2}$ DCF. This prevents the back-diffusion of the dye to the extracellular space. The product of oxidation of nonfluorescent $\mathrm{H}_{2} \mathrm{DCF}$ is highly 
fluorescent DCF. Observed fluorescence is proportional to the concentration of intracellular reactive oxygen species [19]. Briefly, to the 24-well plates containing cells at the density of $1.0 \times 10^{5}$ cells/well POSS in a concentration of $1 \mathrm{mM}$ was added. Cells were incubated with POSS for $24 \mathrm{~h}$ and $48 \mathrm{~h}$ at $37{ }^{\circ} \mathrm{C}$ in humidified atmosphere containing $5 \% \mathrm{CO}_{2}$. After the incubation period cells were washed with PBS. Next, a $2.5 \mu \mathrm{M} \mathrm{H}_{2}$ DCF-DA solution in PBS was added to each well. After 15 min of incubation in dark the solution of $\mathrm{H}_{2}$ DCF-DA was removed, cells were washed with PBS and suspended in $500 \mu \mathrm{L}$ of PBS. The fluorescence of DCF was measured using a Becton Dickinson LSR II flow cytometer.

\subsection{Statistical Analysis}

Data were expressed as a mean \pm SD. Analysis of variance (ANOVA) with Tukey post hoc test was used for multiple comparisons. Statistics were calculated using Statistica software (StatSoft, Tulsa, OK, USA), and p-values $<0.05$ were considered significant.

\section{Conclusions}

POSS in a concentration of $1 \mathrm{mM}$ caused accumulation of cells in the $\mathrm{G}_{0} / \mathrm{G}_{1}$ phase. However, the changes affected less than $10 \%$ of the cell population. Considering the fact that POSS did not increase the amount of neither apoptotic nor necrotic cells, it seems likely that the cells were temporarily arrested in the $\mathrm{G}_{0}$ phase and were still able to divide. This conclusion is supported by the lack of the cytotoxic effect of POSS. Cell viability measured by an MTT assay revealed no changes when compared to control untreated cells. Moreover, POSS did not generate reactive oxygen species. To sum up, it is the first report showing that POSS have no harmful effect on cells. Therefore, POSS can be considered as potential drug delivery system.

\section{Supplementary Materials}

Supplementary materials can be accessed at: http://www.mdpi.com/1996-1944/8/9/6062/s1.

\section{Acknowledgments}

This study was funded by the OPUS project "Oligosilsesquioxane drug nanocarriers" No. UMO-2012/07/B/ST5/02603 supported by National Science Centre, Poland.

\section{Author Contributions}

Anna Janaszewska performed biological experiments and prepared the first draft of the manuscript, Kinga Gradzinska synthesized POSS, Monika Marcinkowska did a part of the biological experiments and edited the manuscript for publication, Wlodzimierz A. Stanczyk supervised the synthesis of POSS and revised the content of the manuscript, Barbara Klajnert-Maculewicz supervised the biological experiments and wrote the final version of the manuscript. 


\section{Conflicts of Interest}

The authors declare no conflict of interest.

\section{References}

1. Kannan, R.M.; Nance, E.; Kannan, S.; Tomalia, D.A. Emerging concepts in dendrimer-based nanomedicine: From design principles to clinical applications. J. Intern. Med. 2014, 276, 579-617. [CrossRef] [PubMed]

2. Cai, X.; Hu, J.; Xiao, J.; Cheng, Y. Dendrimer and cancer: A patent review (2006-present). Expert Opin. Ther. Pat. 2013, 23, 515-529. [CrossRef] [PubMed]

3. Jia, H.Z.; Zhu, J.Y.; Wang, X.L.; Cheng, H.; Chen, G.; Zhao, Y.F.; Zeng, X.; Feng, J.; Zhang, X.Z.; Zhuo, R.X. A boronate-linked linear-hyperbranched polymeric nanovehicle for $\mathrm{pH}$-dependent tumor-targeted drug delivery. Biomaterials 2014, 35, 5240-5249. [CrossRef] [PubMed]

4. Liu, J.; Pang, Y.; Zhu, Z.; Wang, D.; Li, C.; Huang, W.; Zhu, X.; Yan, D. Therapeutic nanocarriers with hydrogen peroxide-triggered drug release for cancer treatment. Biomacromolecules 2013, 14, 1627-1636. [CrossRef] [PubMed]

5. McCusker, C.; Carroll, J.B.; Rotello, V.M. Cationic polyhedral oligomeric silsesquioxane (POSS) units as carriers for drug delivery processes. Chem. Commun. 2005, 28, 996-998. [CrossRef] [PubMed]

6. Tanaka, K.; Inafuku, K.; Naka, K.; Chujo, Y. Enhancement of entrapping ability of dendrimers by a cubic silsesquioxane core. Org. Biomol. Chem. 2008, 6, 3899-3901. [CrossRef] [PubMed]

7. Yuan, H.; Luo, K.; Lai, Y.; Pu, Y.; He, B.; Wang, G.; Wu, Y.; Gu, Z. A novel poly(l-glutamic acid) dendrimer based drug delivery system with both $\mathrm{pH}$-sensitive and targeting functions. Mol. Pharm. 2010, 7, 953-962. [CrossRef] [PubMed]

8. Fong, H.; Dickens, S.H.; Flaim, G.M. Evaluation of dental restorative composites containing polyhedral oligomeric silsesquioxane methacrylate. Dent. Mater. 2005, 21, 520-529. [CrossRef] [PubMed]

9. Motwani, M.S.; Rafiei, Y.; Tzifa, A.; Seifalian, A.M. In situ endothelialization of intravascular stents from progenitor stem cells coated with nanocomposite and functionalized biomolecules. Biotechnol. Appl. Biochem. 2011, 58, 2-13. [CrossRef] [PubMed]

10. Tanaka, K.; Kitamura, N.; Takahashi, Y.; Chujo, Y. Reversible signal regulation system of ${ }^{19}$ F NMR by redox reactions using a metal complex as a switching module. Bioorg. Med. Chem. 2009, 17, 3818-3823. [CrossRef] [PubMed]

11. Kuo, J.H.; Jan, M.S.; Lin, Y.L. Interactions between U-937 human macrophages and poly(propyleneimine) dendrimers. J. Control. Release 2007, 120, 51-59. [CrossRef] [PubMed]

12. Mosmann, T. Rapid colorimetric assay for cellular growth and survival: Application to proliferation and cytotoxicity assays. J. Immunol. Methods 1983, 65, 55-63. [CrossRef]

13. Van Engeland, M.; Ramaekers, F.C.; Schutte, B.; Reutelingsperger, C.P. A novel assay to measure loss of plasma membrane asymmetry during apoptosis of adherent cells in culture. Cytometry 1996, 24, 131-139. [CrossRef] 
14. Soh, N. Recent advances in fluorescent probes for the detection of reactive oxygen species. Anal. Bioanal. Chem. 2006, 386, 532-543. [CrossRef] [PubMed]

15. Cooper, G.M. The Cell: A Molecular Approach, 2nd ed.; Sinauer Associates: Sunderland, MA, USA, 2000.

16. Boonstra, J.; Post, J.A. Molecular events associated with reactive oxygen species and cell cycle progression in mammalian cells. Gene 2004, 337, 1-13. [CrossRef] [PubMed]

17. Verbon, E.H.; Post, J.A.; Boonstra, J. The influence of reactive oxygen species on cell cycle progression in mammalian cells. Gene 2012, 511, 1-6. [CrossRef] [PubMed]

18. Shi, M.; Kwon, H.S.; Peng, Z.; Elder, A.; Yang, H. Effects of surface chemistry on the generation of reactive oxygen species by copper nanoparticles. ACS Nano 2012, 6, 2157-2164. [CrossRef] [PubMed]

19. Naha, P.C.; Byrne, H.J. Generation of intracellular reactive oxygen species and genotoxicity effect to exposure of nanosized polyamidoamine (PAMAM) dendrimers in PLHC-1 cells in vitro. Aquat. Toxicol. 2013, 15, 132-133. [CrossRef] [PubMed]

(C) 2015 by the authors; licensee MDPI, Basel, Switzerland. This article is an open access article distributed under the terms and conditions of the Creative Commons Attribution license (http://creativecommons.org/licenses/by/4.0/). 